\section{Stimulating therapy for obstructive sleep apnoea}

\author{
Patrick J Strollo Jr, ${ }^{1}$ Atul Malhotra ${ }^{2}$
}

The burden of obstructive sleep apnoea (OSA) is increasing due to the worldwide obesity epidemic and the ageing of the population. ${ }^{1} 2$ The treatment of OSA is unsatisfactory for some patients since tolerance of the gold standard treatment positive airway pressure (PAP) is quite variable. Among patients who tolerate PAP, results are excellent; however, effectiveness is limited by variable adherence. ${ }^{3} 4$ Improvements in our understanding of OSA pathogenesis have led to a concept that the mechanism (endotype) underlying OSA is highly variable across individuals such that some patients have primarily an upper airway anatomical problem, whereas others have dysfunction in upper airway dilator muscles, some have unstable control of breathing and some may have combinations of abnormalities. ${ }^{1}$ This realisation has led to the concept of personalised medicine in OSA such that therapies could theoretically be targeted to the mechanism underlying apnoea rather than using a 'one-size-fits-all' approach. ${ }^{5}$

Efforts to improve treatment are ongoing by developing new therapeutic approaches (eg, hypoglossal nerve stimulation). ${ }^{6} 7$ This approach augments the neural output to upper airway dilator muscles as opposed to 'pneumatically splinting' the airway open in the case of PAP therapy or mechanically enlarging the airway as is done with oral appliance therapy. ${ }^{8}$

Strollo et $a l^{9}$ have demonstrated that phasic unilateral electrical stimulation of the hypoglossal nerve is safe and effective in carefully selected participants with moderate-to-severe OSA, who could not accept or adhere to PAP. The durability of the treatment effect has been sustained up to 36 months. ${ }^{10}$ This technology that consists of an implanted pulse generator with sensing and stimulation leads has been approved for commercial use in the USA and Europe.

\footnotetext{
${ }^{1}$ Deaprtment of Medicine and Clinical and Translational Science, University of Pittsburgh, Pittsburgh, Pennsylvania, USA; ${ }^{2}$ Deaprtment of Medicine, University of California San Diego, San Diego, USA

Correspondence to Dr Atul Malhotra, Department of Medicine, University of California San Diego, 9500 Gilman Drive, San Diego 92037, USA; amalhotra@ ucsd.edu
}

The report by Pengo ${ }^{11}$ published in Thorax has approached upper airway stimulation in a different manner. These investigators examined the impact of bilateral submental transcutaneous electrical stimulation (TCES) of the upper airway in patients with OSA. This work is an extension of the feasibility study reported by this group in $2011 .^{12}$

The authors should be commended for a number of strengths related to this study -rigorous design (randomised sham control), careful measurement of sleep and particularly sleep disruption as well as the assessment of participant symptoms related to TCES. The caveats of this report relate to the fact that the primary outcome (4\% oxygen desaturation index) was examined after one night of stimulation in the sleep laboratory, the treatment effect was modest and the active intervention (tonic stimulation) did not impact the apnoea-hypopnoea index in rapid eye movement sleep. ${ }^{13}$

A number of questions remain that merit comment: (1) What muscles/muscle groups are being stimulated? The upper airway has 23 different pairs of muscles with considerable complexity (phasic vs tonic, protruders vs retractors, etc); thus, further efforts will be required regarding precise mechanisms of surface stimulation. (2) What patient endotype responds best to TCES? Considerable work is ongoing suggesting only a subset of patients with OSA have a major issue with upper airway dilator muscle function. ${ }^{14}{ }^{15}$ Thus, one might predict that efforts to augment hypoglossal motor output may be more effective for some patients than for others with OSA depending on underlying mechanism. $^{15}$ (3) Is bilateral stimulation as opposed to unilateral stimulation the better approach? Clinical trials will be required to compare these approaches, although physiological studies (eg, comparing unilateral vs bilateral stimulation on pharyngeal mechanics) would also be valuable in addressing this question. (4) Can one night of treatment with this device refine selection for implantable systems? Such an approach might allow clinicians to determine a priori which patients should undergo the risk and expense of an implantable nerve stimulator. (5) If TCES is used as a stand-alone treatment, what is the long-term impact on sleep, sleep disordered breathing, patient symptoms (ie, snoring, sleepiness and quality of life), patient acceptance/ adherence and long-term cardiovascular/ metabolic risk? ${ }^{16} 17$

While the overall response to TCES was modest, it is conceivable that refining the patient selection by identifying endotypes that might respond to this therapy would strengthen the value of this approach. Future work could possibly incorporate drug-induced sedation endoscopy to examine favourable patterns of airway collapse ${ }^{9}$ or assessment of the physiologic signature of airflow. ${ }^{18} 19$ Such approaches could help to identify those patients with dysfunction in upper airway dilator muscle control who may be responsive to stimulation approaches. On the other hand, patients with OSA with an issue primarily of unstable ventilatory control or low arousal threshold may be predicted to fail treatment targeted just at upper airway dilator muscles. ${ }^{14} 20$

We applaud the authors for moving forward our understanding of electrical stimulation of the upper airway and fuelling further research in this area.

Competing interests PJS is a co-investigator on R01 DK096028-02, R01 HL120354-01A1,

1UH2HL125103-01, U01HL128954 and

5UL1TR000005-09. He has research grants from Philips Respironics, ResMed, Inspire Medical Systems and Jazz Pharmaceuticals. He has received consulting fees from Inspire Medical Systems, ResMed, Emmi Solutions, Jazz Pharmaceuticals, Itamar Medical and the National Football League. AM is PI on NIH RO1 HL085188 and K24 HL132105 and co-investigator on R21 HL121794, R01 HL 119201 and R01 HL081823. As an Officer of the American Thoracic Society, AM has relinquished all outside personal income since 2012. ResMed provided a philanthropic donation to the University of California, San Diego in support of a sleep centre, which AM's division runs.

Provenance and peer review Commissioned; externally peer reviewed.

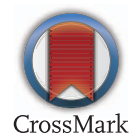

To cite Strollo PJ, Malhotra A. Thorax 2016;71:879880.

Published Online First 3 August 2016

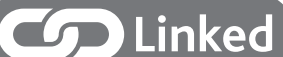

- http://dx.doi.org/10.1136/thoraxjnl-2016-208691

Thorax 2016;71:879-880.

doi:10.1136/thoraxjnl-2016-209077 


\section{Editorial}

\section{REFERENCES}

1 Jordan AS, McSharry DG, Malhotra A. Adult obstructive sleep apnoea. Lancet 2014;383:736-47.

2 Heinzer R, Vat S, Marques-Vidal P, et al. Prevalence of sleep-disordered breathing in the general population: the HypnoLaus study. Lancet Respir Med 2015:3:310-8.

3 Weaver TE, Grunstein RR. Adherence to continuous positive airway pressure therapy: the challenge to effective treatment. Proc Am Thorac Soc 2008;5:173-8.

4 Weaver TE, Mancini C, Maislin G, et al. CPAP Treatment of Sleepy Patients with Milder OSA: Results of the CATNAP Randomized Clinical Trial. Am J Respir Crit Care Med 2012;186:677-83.

5 Smales ET, Edwards BA, Deyoung PN, et al. Trazodone effects on obstructive sleep apnea and non-rem arousal threshold. Ann Am Thorac Soc 2015;12:758-64.

6 Schwartz AR, Barnes M, Hillman D, et al. Acute upper airway responses to hypoglossal nerve stimulation during sleep in obstructive sleep apnea. Am J Respir Crit Care Med 2012;185:420-6.
7 Schwartz AR, Eisele DW, Hari A, et al. Electrical stimulation of the lingual musculature in obstructive sleep apnea. J Appl Physiol 1996;81:643-52.

8 Strollo PJ Jr, Rogers RM. Obstructive sleep apnea. N Engl J Med 1996;334:99-104.

9 Strollo PJ Jr, Soose RJ, Maurer JT, et al. Upper-airway stimulation for obstructive sleep apnea. $N$ Engl J Med 2014;370:139-49.

10 Woodson BT, Soose RJ, Gillespie MB, et al. Three-Year Outcomes of Cranial Nerve Stimulation for Obstructive Sleep Apnea: The STAR Trial. Otolaryngol Head Neck Surg 2016;154:181-8.

11 Pengo MF, Xiao S, Ratneswaran C, et al. Randomised sham-controlled trial of transcutaneous electrical stimulation in obstructive sleep apnea. Thorax 2016:71:923-31.

12 Steier J, Seymour J, Rafferty GF, et al. Continuous transcutaneous submental electrical stimulation in obstructive sleep apnea: a feasibility study. Chest 2011;140:998-1007.

13 Mokhlesi B, Finn LA, Hagen EW, et al. Obstructive sleep apnea during REM sleep and hypertension.
Results of the Wisconsin Sleep Cohort. Am J Respir Crit Care Med 2014;190:1158-67.

14 Deacon NL, Jen R, Li Y, et al. Treatment of obstructive sleep apnea. Prospects for personalized combined modality therapy. Ann Am Thorac Soc 2016;13:101-8.

15 Malhotra A. Hypoglossal-nerve stimulation for obstructive sleep apnea. N Engl J Med 2014;370:170-1.

16 Tachikawa R, Ikeda K, Minami T, et al. Changes in energy metabolism after continuous positive airway pressure for obstructive sleep apnea. Am J Respir Crit Care Med 2016.

17 Ayas NT, Owens RL, Kheirandish-Gozal L. Update in sleep medicine 2014. Am J Respir Crit Care Med 2015;192:415-20.

18 Strohl KP, Butler JP, Malhotra A. Mechanical properties of the upper airway. Compr Physiol 2012:2:1853-72.

19 Malhotra A, Butler JP, Wellman A. The pharyngeal airway: is bigger really better? Chest 2012;141:1372-5.

20 Edwards BA, Eckert DJ, McSharry DG, et al. Clinical predictors of the respiratory arousal threshold in patients with obstructive sleep apnea. Am J Respir Crit Care Med 2014;190:1293-300. 